\title{
LITORAIS DA PSICANÁLISE
}

\section{Ana Costa \\ Universidade do Estado do Rio de Janeiro, Rio de Janeiro, Brasil}

RESUMO: Este trabalho se propõe a abordar algumas fronteiras estabelecidas pelo discurso analítico, principalmente com o campo da literatura. Sua principal referência se sustenta no tema dos "litorais", seguindo a proposição lacaniana criada pelo neologismo "lituraterra". Essa proposição, além de permitir construir interfaces da psicanálise com outros campos, também é o suporte para a produção dentro da própria psicanálise. Sua especificidade é a de constituir seu sujeito passando pela proposta de uma "extimidade", numa torsão na concepção corriqueira do dentro e fora. O tema que permitirá situar a construção dessas bordas situa-se na questão da escrita.

PALAVRAS-CHAVE: letra, escrita, pulsão, inscrição.

\section{PSYCHOANALYSIS LITTORALS}

\begin{abstract}
This work intends to discuss some frontiers established by the psychoanalytical discourse, mainly with literature as a privileged field of dialogue. Its principal reference is supported by the subject of the "littoral", following the Lacanian proposition created by the neologism "lituraterre". This proposition allows us to build interfaces between psychoanalysis and other fields, and it is also the support for the production inside psychoanalysis itself. This approach is a reversion of the ordinary conception of the relationship between internal / external. The subject that will allow us to situate the construction of these edges concerns the question of the writing.
\end{abstract}

KEYWORDS: letter, writing, instinct, inscription

Este trabalho se propõe a transitar por algumas bordas, que estabelecem limites ao discurso analítico, principalmente na fronteira com o campo da literatura. Nomeio essas bordas de "litorais" seguindo a proposição lacaniana situada no texto "Lituraterra" (Lacan, 2003). Essa proposição, além de permitir construir interfaces da psicanálise com outros campos, também é o suporte para produção dentro da própria psicanálise, cuja especificidade constitui seu sujeito passando pelo tema da "extimidade", numa torsão necessária na concepção corriqueira do dentro e fora, como bem o situa Lacan (1988). O tema que me permitirá situar a construção dessas bordas diz respeito à questão da escrita.

Como estabelecer relações entre campos distintos mantendo-se a singularidade do próprio campo? Podese dizer que já desde Freud a psicanálise se propôs a isso. Se por um lado este autor escreveu trabalhos inspirados em questões literárias (ou mesmo antropológicas), isso aconteceu sempre em função de uma clínica, que implicava necessariamente o campo do inconsciente. É desde esses fundamentos, já estabelecidos historicamente, que me proponho trazer as contribuições da psicanálise ao tema da escrita. Tomando o título do trabalho, litorais contém a referência lacaniana a territórios heterogêneos que, no entanto, situam na escrita seu ponto de amarração.
Começarei por abordar as dificuldades inerentes à inscrição de uma escrita num campo que lhe corresponda. No campo literário, por exemplo, quantas vezes surgem as indagações: será isto literatura? Muitos escritores já reconhecidos - Proust entre eles - tantas vezes se perguntaram (ou perguntam) se são ou não escritores. Blanchot (2005) formula o que denomina de "dúvida patética" de Proust, quando, já reconhecido e tendo publicado vários de seus livros, ainda se indagava sobre seu "ser" de escritor. Embutida nessa dúvida, nessa indagação que atinge mesmo o cerne de sua criação, está talvez a incerteza sempre em causa na repetição do ato de criação.

De outro lado, testemunhos da clínica psicanalítica deparam-nos com uma questão que se desborda na psicose: o que significa a compulsão a escrever? Retomo, aqui, o termo colocado na abertura deste artigo, trazendo a referência ao neologismo "lituraterra", inventado por Lacan. Nele, o autor transita por uma colocação do escritor James Joyce: a de que ele produzia a letra como lixo ("a letter" - "a litter"). O inusitado dessa colocação nos evoca a complexidade da inscrição da letra nos diferentes campos de saber produzidos pela cultura. Essa dificuldade diz respeito a uma questão específica e que tem relação com a clínica da psicose: a letra pode ser produzida desamarrada de 
um endereçamento ao laço social. Ou seja, não é certo que um escrito - independente de sua qualidade - tenha uma inscrição social pelo endereçamento que sua leitura convoque. Uma escrita delirante não supõe uma leitura. Lidamos, nessa escrita, com um fechamento, que se apresenta inicialmente - se não encontra uma produção de transferência - desamarrada de qualquer relação ao outro.

Com isso, recortamos dois elementos que concernem à condição da letra, tal qual se apresenta na especificidade de sua abordagem pela psicanálise: a condição de resto e a tentativa de inscrição. A dificuldade atinente ao tema da inscrição diz respeito à necessidade de transmitir uma experiência que é - por princípio intransmissível, na medida em que contém um apoio corporal. O tema do "apoio", aqui, situa-se de par com a proposição freudiana da pulsão (Freud, 1915/1973). Desdobra-se nas referências às formações do inconsciente, ou mesmo na angústia e no delírio. Num primeiro momento, podemos mesmo surpreender-nos que seja possível transmitir essa ordem de experiências tão reduzidas. Mesmo que se tenha tornado um campo de expressão na psicanálise, não deixa de surpreender-nos que seja possível transmitir a experiência solitária do sofrimento psíquico, como o é um medo noturno expresso como "irracional", por exemplo. Situa-se aqui um litoral entre essas experiências e a racionalidade. Por vezes, nenhuma das ficções que nos amparam é suficiente para transpor esse litoral. Não há continuidade possível entre razão e angústia. Para que alguém possa ser transportado de um lugar para outro - ou seja, da experiência reduzida a seu corpo, para uma significação compartilhada - é preciso ser acompanhado, produzir um leitor dessa experiência. Nesse ponto a clínica psicanalítica encontra-se com a experiência literária, na medida em que isso também tem a ver com a possibilidade de produzir literatura. Ou seja, situa-se nessa condição em que a escrita é primeiro corporal e faz parte de nossas experiências mais ordinárias.

A experiência da clínica psicanalítica nos atesta que aquele que vai consultar um analista está colocado na posição de precisar construir um leitor, que possa ser incluído no endereçamento de sua letra, que, antes de tudo, é pulsional. O que significa na possibilidade de encontrar um outro, a quem o sujeito se dirija, que não se posicione como exterioridade ao campo da transferência construída. Do lado do sofrimento psíquico encontramos uma grande dificuldade em estabelecer esse campo mesmo. Como é possível transmitir uma experiência que, em princípio, é solitária, onde na maior parte das vezes o sujeito está capturado na redução ao próprio corpo? O que significa produzir a letra, como repetição mesma do exercício pulsional, sem que consiga chegar a um endereço, numa experiência que se esgota em si mesma? O cerne desta questão se coloca tanto para a clínica psicanalítica, quanto para a produção literária, que têm por princípio a condição de que seja possível transmitir experiências que a priori são intransmissíveis.

A expressão lacaniana para a transferência como "sujeito suposto saber" (Lacan, 1985) não diz apenas do lugar do analista, mesmo que o analisando o suponha imaginariamente ali. Essa expressão indica - mais que nada - que há um saber que acossa o sujeito, em relação ao qual ele não tem condições de apropriação. É uma posição signatária da condição da escrita que interpela o sujeito, que indica um saber do qual ele é objeto, numa absoluta solidão frente a um gozo que o invade e que ele precisa dominar. Nessa condição, ele não tem como se apropriar dos limites de seu corpo sem que haja algo que o suporte. Essas expressões que lhe acossam dizem que algo sabe nele. Quando Lacan faz a proposição para a transferência incluindo um saber, está apontando a expressão de um saber que faz de alguém objeto. O percurso de análise vai produzir um sujeito num saber que é exteriorizado nas diversas formações de que o sujeito padece.

Assim, na transferência é possível produzir um leitor ao endereço da letra. Nem sempre o sujeito tem êxito nessa construção e temos produções com mais dificuldade na constituição de um leitor. É o caso da psicose, onde o sujeito padece delirantemente disso que o acossa, sem porto de chegada. Na paranóia, que é uma psicose mais amarrada, no sentido de que suas construções produzem consistências, a relação se estabelece com o Outro numa posição de certeza (Lacan, 1998c). Nesse sentido, a certeza por vezes dispensa destinatários para sua letra. Por outro lado, só conseguimos reconhecer um endereçamento, como tendo estado sempre lá, quando essa letra chega a um leitor, a posteriori. A insistência da letra se dá num sentido de retorno ao próprio corpo, como padecimento na repetição. Lacan (1998b) já destaca isso no texto que constitui sua proposição de princípios ao campo da psicanálise, situado como função e campo da fala e da linguagem, onde encontramos expressões do corpo capturado no sintoma:

Hieróglifos da histeria, brasões da fobia, labirintos da Zwangs-neurose; encantos da impotência, enigmas da inibição, oráculos da angústia; armas eloqüentes do caráter, chancelas da auto-punição, disfarces da perversão - tais são os hermetismos que nossa exegese resolve, os equívocos que nossa invocação dissolve, os artifícios que nosso discurso absolve... (p. 282)

Nessa passagem destaca-se o hibridismo da referência à letra nas formações clínicas, nas quais se dá a captura da gramática da pulsão numa estrutura discursiva. 
Lacan propõe que toda letra tem endereço, ou seja, sua própria produção resulta de um endereçamento pulsional, alienado ao Outro desde o início. É nesse sentido que a leitura é anterior a uma escrita. $\mathrm{Na}$ aula do seminário de 1972, intitulada Lituraterra (Lacan, 2003), encontramos um grande debate entre Lacan e Derrida a esse propósito. Lacanianamente falando, a letra traz seu endereço, o que significa ser possível uma leitura, mesmo que não seja do campo do sentido, produzindose do lado do objeto voz no canto, por exemplo. Sobre esse tema, precisamos sempre valer-nos da referência a uma temporalidade, na medida em que é pela produção de atos que podemos testemunhar, a posteriori, o que estava antes. Se não houver a construção do leitor, incluído no endereçamento, fazendo a passagem pelo outro que legitima sua produção, o sujeito não sairá do isolamento de suas repetições, ou mesmo da circunscrição ao corpo próprio.

No caminho das proposições até aqui, cabe desenvolver um pouco mais o estatuto da letra para a psicanálise. Para sua construção, Lacan (1998c) tentou diferenciar letra e significante, partindo da referência fértil a muitos autores. Desse seu diálogo, ele importou para a psicanálise diferentes linguagens, abrindo as formas fechadas de apresentação do campo analítico. Mas, com esse exercício, também influenciou os outros campos por onde circulou. Assim, é por uma relação com a lingüística que ele tenta diferenciar letra e significante. Este último tema estava completamente ligado, para o autor, à função da fala e à possibilidade que se constituísse, nessa função, a produção do sujeito. Falar é transmitir ao interlocutor a possibilidade de um endereçamento. Fazer de um outro suporte de um endereçamento implica na saída de uma referência exclusivamente auto-erótica, sendo esse o principal motor da função da fala. A passagem pelo desenvolvimento da lingüística proporcionou a Lacan as condições para precisar o que é o significante, enquanto produção de sujeito, nesse exercício - com um outro - da função da fala.

Por outro lado, temos o tema da pulsão - das relações ao corpo - índice sempre presente da objetalização do sujeito, onde a relação ao Outro é diferente. Neste campo ele situa a letra. A letra feminiza (Lacan, 1998d): o sujeito se situa como objeto de alguma coisa, aprisionado no seu momento de maior objetalização, situado numa posição na qual está submetido. O tema da letra é situado do lado dos orifícios pulsionais. Pulsão, para Lacan (1985), é a possibilidade de um exercício que esburaca o corpo, constituindo apoio para a troca com o outro. Na boca, por exemplo, a ingestão não se situa somente na ordem da necessidade, mas implica toda uma referência cultural: o que faz parte dos significantes que estão no Outro e que situam as possibilidades cultu- rais inscritas na satisfação das necessidades. É o que é proposto como desnaturação do sujeito pela linguagem. A boca, além da ingestão, traz a fala. O ouvido escuta a fala, mas também a música, a construção de intervalos: esses intervalos funcionam como apoio dos objetos pulsionais. A voz é um objeto pulsional, que faz enlace com outro, para o qual se dirige na sua emissão. Na voz o outro está colocado, quando se fazem as escansões que lhe dão a musicalidade, onde o endereço ao Outro está incluído. O olhar é um objeto, porque carrega a relação ao outro, a ser olhado. No entanto é também um objeto corporal. Assim, a letra é dessa ordem: resulta do que tem incidência na produção de nossos orifícios corporais, onde se constitui o índice de nossa alienação maior. A conformação do corpo é modelada pela complexidade dessas relações, sustentadas pela articulação do que Lacan propôs como três registros: Real, Simbólico e Imaginário.

Pensar no tema da letra implica em situar o que faz borda no corpo: o que diz respeito ao campo do litoral, do encontro Simbólico/Real. O endereçamento da letra tem relação com a leitura que o Outro primordial constrói, em que ao mesmo tempo erotiza e produz amparo. É por essa razão que Lacan propõe que primeiro está a leitura: é desta leitura do Outro primordial que vem a possibilidade do recorte dos orifícios do corpo. É nesse ponto que somos seres de linguagem. Que nosso corpo não funciona se não for pela incidência do Outro no nosso corpo, no que Lacan desenvolve a partir da proposição de lalangue. Encontramos nesta a marca do Outro primordial.

É importante referir que essa leitura não é uma produção de sentido, sendo absolutamente enigmática. Diremos melhor que é a inscrição de traços da fala materna no corpo da criança. A partir dessa alienação maior - dessa colagem do corpo a esse leitor que precede um sujeito - constitui-se a possibilidade da dialética. Somente nesses movimentos de relação com um outro - o semelhante a quem é dirigida a fala - é que se dá uma apropriação disso que se manifesta primeiro corporalmente. O significante enquanto produção do sujeito é da natureza desse segundo movimento, enquanto exercício da função da fala.

Outro elemento a sublinhar - referido à questão da fala - diz respeito a uma diferenciação entre o que produz experiência e algo situado do lado da comunicação. A comunicação, em si, não produz experiência. Ela pode ser assimilada, mas descartada. Pode ser somente ruído, mesmo que possa ser agradável, mesmo que possa satisfazer nossa estética. Visitas culturais, leituras de livros: não é certo que esses movimentos produzam experiência. Não é sempre que isto acontece. Nas obras culturais, nas artes plásticas ou teatros - mesmo quando estes convocam o expectador a ser ativo - a atividade 
pode não se traduzir em experiência, mesmo quando somos mais ativos que contemplativos. Um ponto de implicação é distinto dessas atividades: ou tocando no inexplicável, ou produzindo angústia, ou destravando algo de nossa criação. Ou seja, é uma implicação que nos leva a produzir algo.

Se tomarmos a posição da mídia na relação à comunicação, sua suposição é de que nesta não há mal entendido. Esse pressuposto é impossível, porque a comunicação é prenhe de mal entendido, como tudo o que é da ordem da linguagem. Numa comunicação, por exemplo, não se está interessado em como o outro vai reagir: se está interessado em que sejam produzidos enunciados que não deixem dúvidas. Essa suposição exclui duas coisas: o impossível de tudo dizer e o endereçamento que inclua o outro. A relação com os absolutos contém esses pressupostos.

Retomemos a relação entre a produção da letra, na constituição das bordas - no furo do saber - e a possibilidade de inscrição da letra num campo discursivo. É essa inscrição que permite a produção singular de uma linguagem, constituindo um enlace do pulsional circunscrito a esse campo. A literatura, por exemplo, permite transmitir algo dessa experiência tão solitária do sujeito com sua pulsionalidade fazendo um sulco - produto do discurso - por onde pode escoar algo de uma significação que se enlace ao campo do Outro. A literatura permite criar a partir da produção de uma letra, algo que se não fosse essa circunscrição a esse campo não teria encontrado lugar de expressão, de enlaçamento. É esse enlace que traz a possibilidade de se fazer um passe de algo incomunicável, incompreensível, algo que se perde como resto do corpo. Por aqui retomo a diferenciação entre significante e letra. A letra como produzindo as bordas do corpo e o enlace significante como permitindo que a letra tenha um escoamento, dentro de um campo discursivo específico.

Tomemos a filosofia como exemplo de um campo. Sabe-se quando é um filósofo que está falando na medida em que reconhecemos uma amarração particular da letra ao saber. Não se trata exclusivamente de uma questão de conhecimento, mas de posição na transmissão desse saber. Isso faz com que cada um, ao falar desde seu campo, possa ser reconhecido como referido ao saber circunscrito a esse campo. Como se sabe? Pela posição daquele que fala e na qual está implicada numa inscrição específica da letra no discurso, que recorta, dessa forma, um saber na linguagem. Isso se situa não somente na produção de um conhecimento, mas numa estrutura que se repete para diferentes sujeitos. Também implica que esse campo, criado por uma posição específica do discurso, aliena os sujeitos que ali se inscrevem. É o que faz com que sua produção significante corra pelos sulcos do real - conforme propõe Lacan em Lituraterra - de uma maneira determinada, que permite que nós a reconheçamos na sua produção. Essa possibilidade de reconhecer já traz o apaziguamento de algo que em si é dispersão.

Quando se sabe que se está inscrito num campo discursivo já é apaziguador, porque isso dá suporte de linguagem a algo que pode produzir despedaçamento do corpo. Isso diz respeito tanto ao campo da arte, quanto da literatura e da psicanálise. A maneira como cada campo do saber produz seus sulcos permite que os sujeitos que ali se inscrevam partam dali para fazer sua amarração singular da letra: alargando os limites do campo, tencionando-os, mas sempre circunscritos a ele. Temos de início uma estrutura discursiva que precisa da experiência de cada um para dar corpo à linguagem.

A referência ao tema dos discursos foi abordada por Lacan (1992), como se sabe, a partir de um diálogo com Foucault. Neste diálogo ele ficou interessado em pensar a posição do mestre no discurso, propondo, a partir daí, quatro estruturas discursivas como determinantes da posição do sujeito no campo da linguagem. Não é certo que cada discurso esteja situado no lugar onde sua designação se coloca. Por exemplo, não é certo que o discurso universitário esteja na universidade, pode estar em outras instituições. $O$ discurso da histérica, por exemplo, não está colado à sintomática histérica. Os discursos não estão colados ao lugar de onde Lacan se inspirou para nomeá-los. De outro lado, por que quatro discursos? Porque Lacan jogou com dois determinantes fundamentais da constituição do sujeito: de um lado, a determinação significante pelo S1 -S2; de outro, a posição do sujeito no fantasma. Aqui se situa a função que exerce a fantasia na amarração de nossos orifícios corporais a partir da desnaturação da linguagem. Esses são os determinantes fundamentais do sujeito. $\mathrm{O}$ discurso do mestre insere o sujeito na linguagem, que recorta a letra pulsional, inserindo-a nas relações a partir da fantasia.

O tema do sujeito para a psicanálise toma sua referência ao significante, com sua produção no lugar mesmo da repetição - onde o sujeito apresenta sua condição singular de alienação à linguagem. Essa produção significante tem toda importância, na medida em que enlaça simbólico e real: significante e ato (que, por outro lado, são vertentes em causa na repetição). Nessa questão encontramos uma proposição que Lacan desenvolve no Seminário 11 (Lacan, 1985), onde diz que o inconsciente não é ôntico, é ético. A menção à ontologia diz respeito a que o sujeito sempre está tentando capturar a letra numa apreensão de seu ser. $\mathrm{O}$ aspecto extremamente fugaz e evanescente, em que implicam nas determinações de ser de linguagem, fazem com que o sujeito tenha essa inclinação por tentar estabelecer algo de fixado. No entanto, se conseguimos pensar no 
que nos determina, vamos chegar a esse estatuto ético, no sentido em que ele se situa por relação à ética de cada discurso. Isso está dentro do que abordamos anteriormente: nossos atos são inscritos discursivamente.

Como pensar nesse estatuto ético proposto por Lacan? Podemos situar a ética - de uma maneira aproximativa - como o que dirige os atos do sujeito. A construção da referência ao ser é determinada pela posição num discurso: isso que faz a ética de nossos atos determinando nossas escolhas. Lidamos, aqui, com o que faz limite, que implica o impossível e que, por outro lado, é isso que abre o campo das possibilidades. Aética se determina pelo que é impossível em cada discurso. O impossível não se confunde com a moral. Tentamos traduzi-lo para o campo da moral, na medida em que funcionamos pela encarnação no Outro de atributos e censuras. A ética é a linha traçada pelo que amarra o sujeito no discurso. Nesse sentido traça uma borda, fazendo o contorno do impossível. A partir daí o sujeito precisa dar as razões, precisa preencher o vazio, criado por essa borda, com censuras e proibições.

A literatura também produz uma determinada forma de inscrição discursiva, por isso se sabe que é literatura. Lacan, no final de sua produção (Lacan, 2007), dirige seu interesse pela relação do sujeito com sua produção, enquanto alienação mais radical ao objeto pulsional. Também a clínica psicanalítica fica afetada por essa condição mais radical e é aí onde ele se encontra com Joyce. Como se sabe, por exemplo, que o que Joyce produz é literatura? Apesar de toda a dificuldade dos leitores transporem as páginas dos livros que ele escreveu esse algo que não fica completamente capturado (porque produz enigmas), certamente ali ele se dirige a uma busca de inscrição no campo literário. Joyce conseguiu produzir a inscrição na literatura de um gozo que transbordava, de difícil expressão. Esse gozo não é de ordem fantasmática, se dá na constituição mesma de seu ato de destruição e esburacamento das palavras. Se a inscrição dessa produção foi possível é na medida em que o jogo com a musicalidade da língua retoma sua dimensão primária de leitura. Com ele, temos acesso a essa dimensão mais radical do trabalho da letra, mas que, de qualquer maneira, está inscrita num campo. $\mathrm{O}$ ato do escritor tem uma dimensão ética, na medida em que produz inscrição de seu produto - essa dimensão que poderia ser a mais solitária de seu gozo - num campo compartilhado, criando cultura.

Isso também diz respeito ao campo da psicanálise, que se transforma pela busca da inclusão de atos singulares, situados pela inscrição do sujeito. Por outro lado, é isso que movimenta uma estrutura discursiva, que não é pensável sem que cada sujeito alargue seus pressupostos. O exercício da clínica psicanalítica faz movimentar esses pressupostos. Nesse sentido, a criação de algo novo está sempre em causa.

\section{Referências Bibliográficas}

Blanchot, M. (2005). O livro por vir. São Paulo: Martins Fontes. Freud, S. (1973).La pulsión y sus destinos. In Obras Completas (Vol. II, pp. 2040-2052). Madrid: Biblioteca Nueva.

Lacan, J. (1985). O seminário, Livro 11: Os quatro conceitos fundamentais da psicanálise. Rio de Janeiro: Jorge Zahar Editor.

Lacan, J. (1988). O seminário, Livro 7: A ética da psicanálise. Rio de Janeiro: Jorge Zahar Editor.

Lacan, J. (1992). O seminário, Livro 17: O avesso da psicanálise. Rio de Janeiro: Jorge Zahar Editor.

Lacan, J. (1998a). A instância da letra no inconsciente ou a razão desde Freud. In Escritos (pp. 238-324). Rio de Janeiro: Jorge Zahar Editor.

Lacan, J. (1998b). De uma questão preliminar a todo tratamento possível da psicose. In Escritos (pp. 537-590). Rio de Janeiro: Jorge Zahar Editor.

Lacan, J. (1998c). Função e campo da fala e da linguagem em psicanálise. In Escritos (pp. 496-533). Rio de Janeiro: Jorge Zahar Editor.

Lacan, J. (1998d). O seminário sobre "A carta roubada". In Escritos (pp. 13-66). Rio de Janeiro: Jorge Zahar Editor.

Lacan, J. (2003). Lituraterra. In Outros Escritos (pp. 15-25). Rio de Janeiro: Jorge Zahar Editor.

Lacan, J. (2007). O seminário, Livro 23: O Sinthoma. Rio de Janeiro: Jorge Zahar Editor.

Ana Costa é Professora do PPG em Psicanálise da UERJ, analista membro da Associação Psicanalítica de Porto Alegre (APPOA), autora dos livros A ficção do si mesmo. Interpretação e ato em psicanálise (Ed. Cia de Freud, 1998); Corpo e escrita. Relações entre memória e produção da experiência (Ed. Relume-Dumará, 2001); Tatuagem e marcas corporais. Atualizações do sagrado (Ed. Casa do Psicólogo, 2003); Sonhos (Ed. Jorge Zahar, 2006); Clinicando (APPOA, 2008).

E-mail: ammcosta@terra.com.br

\section{Litorais da psicanálise}

Ana Costa

Recebido em: 23/06/2008

Aceite em: 08/10/2008 